\title{
Drug Repurposing for Cancer Therapy
}

\section{Carlos M. Telleria*}

Division of Basic Biomedical Sciences, Sanford School of Medicine of The University of South Dakota, 414 East Clark Street, Vermillion, SD 57069, USA

Keywords: Drug repurposing; Drug repositioning; Cancer therapy

\section{Background}

In the mid-1980s, a French company geared its efforts toward developing a synthetic steroid capable of blocking the glucocorticoid receptor in order to potentially treat Cushing's syndrome. Preclinical studies revealed that the compound developed, termed RU-38486, was indeed a potent antiglucocorticoid agent [1], yet with a caveat: if given to pregnant animals, it terminated pregnancy [2-4]. Thus, a compound originally developed for treating one disease, rapidly acquired a different identity, was named mifepristone and investigated in depth for its abortifacient properties through the blockage of uterine progesterone receptors $[4,5]$. In other words, developed with one intended use, RU-38486 was repurposed for another modality of use even before gaining approval for medical usage. In the US, the Food and Drug Administration (FDA) approved mifepristone for chemical termination of early pregnancy in September 2000 [6]. It took 12 more years for the FDA to support mifepristone for its intended original use, the treatment of Cushing's disease. In February 2012, the FDA approved mifepristone to control hyperglycemia in adults with endogenous Cushing's syndrome and not eligible for surgery [7].

The case of mifepristone is an evolving example of many in drug repurposing, rescue, or repositioning efforts, which entail the development of a new modality of use for an existing therapeutic compound-i.e., given a new use to an old molecule. There are many compounds that have been developed by pharmaceutical companies and academic institutions throughout the years, in addition to many natural compounds, that remain without a concrete clinical application; they are abandoned or underinvestigated compounds [8-10].

Many preclinical developments promise further repurposing for RU-38486, including other reproductive-related applications such as oral contraception, menstrual regulation, and emergency contraception and the amelioration of psychiatric and endocrine disorders $[11,12]$. Furthermore, the compound is emerging as a treatment for endometriosis and uterine fibroids [13]. More recently, we and others have provided ample evidence for the potential effectiveness of RU38486 in oncology by blocking the growth of several cancer cell types [14-18,19].

The case of RU-38486 is just one example depicting the potentiality of relatively rapid translation to the clinic applicable to many abandoned compounds or compounds developed for other purposes. For instance, metformin, a drug developed and approved to treat type II diabetes, is currently being intensively investigated to treat breast cancer [20,21]. Another, perhaps enigmatic case, is that of thalidomide, currently approved for the treatment of multiple myeloma [22-25]. Thalidomide was originally developed for the treatment of morning sickness in pregnant women; yet, it had devastating teratogenic side effects manifested with severe birth defects $[26,27]$.

Discoveries in cancer biology facilitated the development of the first targeted therapy, imatinib mesylate (a.k.a. Gleevec), which blocks a constitutive active kinase uniquely expressed in chronic myeloid leukemia (CML) harboring the Philadelphia chromosome translocation [28]. Yet, the success of Gleevec has been limited by the fact that the disease evolves in response to the drug, developing new mutations in the $\mathrm{Bcr}-\mathrm{Abl}$ protein kinase, making the continuous development of new drug derivatives a necessity $[29,30]$. However, the development of new drugs is extremely costly and there is certainly a gap between the resources invested in drug development and their translatability into longer survival for cancer patients. Repurposing existing drugs has to its advantage the fact that many toxicological studies have been already done, which reduces the time and cost of approving the compounds for clinical use. For example, the repurposing of RU-38486 was accelerated by the fact that all previous toxicological studies had been done before its approval for early termination of pregnancy. Thus, before being approved for Cushing's syndrome, the safety and efficacy of the drug was evaluated in a clinical trial of only 50 patients; this is because the compound had the backup of extensive literature on side effects when used for short term as a contraceptive agent, or for long term in clinical trials in patients with inoperable meningiomas that have taken the drug for several years and had mild toxicity considering the clinical benefits [31].

In order to cooperate in utilizing the existing resources to its maximum, the National Institutes of Health (NIH) recently created the National Center for Advancing Translational Sciences (NCATS) $[10,32]$. In terms of drug repurposing, the new Institute developed a funding mechanism to investigate potential new clinical applications, including cancer therapy, for a group of abandoned drugs in agreement with the companies holding the propriety rights [32]. NCATS just launched in July 2012 a pilot NIH-Industry program for discovering new therapeutic uses of existing molecules in which the NIH will collaborate with several pharmaceutical companies that will make a list of 58 drugs available to basic researchers [33]. This is good news for patients with so-named orphan diseases, i.e, those with low prevalence and for which R\&D from traditional pharmaceutical companies is very limited. Within such orphan diseases, many cancer types can be included. There are additional signs of government-controlled institutions becoming more creative in the process of drug approval. For instance, going back to mifepristone and its relatively rapid approval to treat Cushing's syndrome (also an orphan disease with a prevalence of $\sim 5,000$ patients in the US), the FDA utilized an approach in which

*Corresponding author: Carlos M. Telleria, Division of Basic Biomedica Sciences, Sanford School of Medicine of The University of South Dakota, 414 Eas Clark Street, Vermillion, SD 57069, USA, E-mail: Carlos.Telleria@usd.edu

Received July 19, 2012; Accepted July 21, 2012; Published July 21, 2012

Citation: Telleria CM (2012) Drug Repurposing for Cancer Therapy. J Cancer Sci Ther 4: ix-xi. doi:10.4172/1948-5956.1000e108

Copyright: (c) 2012 Telleria CM. This is an open-access article distributed under the terms of the Creative Commons Attribution License, which permits unrestricted use, distribution, and reproduction in any medium, provided the original author and source are credited. 
the pharmaceutical that develops the medicine, has the total right of access to the entire of patients being attended by endocrinologists in the US, and distributes the medicine via a centralized pharmacy. In this manner, the FDA made appealing to a small company one of the limitations which forces many pharmaceuticals to put back compounds in shelves-their reduced marketability. For instance, who would invest in developing a drug exclusively to target ovarian cancer when it has a diagnosis rate of $\sim 22,000$ patients per year? Nevertheless $70 \%$ of those patients will die of the disease within 5 years of diagnosis due to a lack of alternative treatment approaches. Together, academic institutions, the government, and the pharmaceutical industries should work in coordination to become more creative and provide solutions to members of society that did not choose to develop an orphan disease, such as many cancers.

Researchers have now access to high throughput screenings to test old drugs and natural compounds for their potential anti-cancer properties; however, researchers should also have access to such chemicals. The NCATS is paving the way towards the access of these drugs, and the initiative is welcome. Still, as a society, we should enhance the process of discovery by creating a more dynamic feedback system between academics, clinicians, patients, patient advocates, funding institutions, and the private pharmaceutical sector. Bedside observations in terms of signs and symptoms of patients being treated for a special condition may underscore off-target effects of a drug. Some of these observations could lead to the use of certain compounds for preventing cancer development. For example, it is well documented by epidemiological studies that women who have used progestin-based contraceptive pills continuously for at least 5 years, have reduced risk to develop ovarian cancer for 20 years [34,35]. Clinicians should develop new hypotheses based on observations and interviews with patients, and basic researchers should go back to the bench to test compounds with anticipated anti-growth properties. Let's not forget that the most popularly used anticancer agent, platinum, was discovered serendipitously when microbiologists were investigating the behavior of bacteria upon changes in voltage and observed growth inhibition due to electrolysis products from a platinum electrode [36-39]. Cancer patients deserve that we scientists utilize all tools at our disposal, from rational drug design for targeted therapy all the way to serendipitous observations in the laboratory, the clinic, and by the patients themselves. Hopefully, using all these resources, we will convert cancer into a treatable chronic disease. The current technological armamentarium provides cancer researchers with a unique opportunity to find new targets for old synthetic, abandoned compounds or newly discovered natural products.

\section{Acknowledgements}

This work was supported by National Cancer Institute Grant R15CA164622. I thank Mr. Nahuel Telleria for the edition of the manuscript.

\section{References}

1. Gagne D, Pons M, Philibert D (1985) RU 38486: a potent antiglucocorticoid in vitro and in vivo. J Steroid Biochem 23: 247-251.

2. Baulieu EE, Ulmann A, Philibert D (1987) Contragestion by antiprogestin RU 486: a review. Arch Gynecol Obstet 241: 73-85.

3. Bosc MJ, Germain G, Nicolle A, Mouren M, Philibert D, et al. (1987) Control of birth in rats by $R U$ 486, an antiprogesterone compound. J Reprod Fertil 79: 1-8.

4. Ulmann A, Dubois C, Philibert D (1987) Fertility control with RU 486. Horm Res 28: $274-278$.
5. Rauch M, Loosfelt H, Philibert D, Milgrom E (1985) Mechanism of action of an antiprogesterone, RU486, in the rabbit endometrium. Effects of RU486 on the progesterone receptor and on the expression of the uteroglobin gene. Eur J Biochem 148: 213-218.

6. Historical Information on Mifepristone (marketed as Mifeprex)

7. FDA approves Korlym for patients with endogenous Cushing's syndrome.

8. Carley DW (2005) Drug repurposing: identify, develop and commercialize new uses for existing or abandoned drugs. Part II. IDrugs 8: 310-313.

9. Carley DW (2005) Drug repurposing: identify, develop and commercialize new uses for existing or abandoned drugs. Part I. IDrugs 8: 306-309.

10. Weir SJ, DeGennaro LJ, Austin CP (2012) Repurposing approved and abandoned drugs for the treatment and prevention of cancer through publicprivate partnership. Cancer Res 72: 1055-1058.

11. Benagiano G, Bastianelli C, Farris M (2008) Selective progesterone receptor modulators 3: use in oncology, endocrinology and psychiatry. Expert Opin Pharmacother 9: 2487-2496.

12. Benagiano G, Bastianelli C, Farris M (2008) Selective progesterone receptor modulators 2: use in reproductive medicine. Expert Opin Pharmacother 9 : 2473-2485.

13. Moller C, Hoffmann J, Kirkland TA, Schwede W (2008) Investigational developments for the treatment of progesterone-dependent diseases. Expert Opin Investig Drugs 17: 469-479.

14. Goyeneche AA, Caron RW, Telleria CM (2007) Mifepristone inhibits ovarian cancer cell growth in vitro and in vivo. Clin Cancer Res 13: 3370-3379.

15. Freeburg EM, Goyeneche AA, Seidel EE, Telleria CM (2009) Resistance to cisplatin does not affect sensitivity of human ovarian cancer cell lines to mifepristone cytotoxicity. Cancer Cell Int 9: 4.

16. Freeburg EM, Goyeneche AA, Telleria CM (2009) Mifepristone abrogates repopulation of ovarian cancer cells in between courses of cisplatin treatment Int J Oncol 34: 743-755.

17. Tieszen CR, Goyeneche AA, Brandhagen BN, Ortbahn CT, Telleria CM (2011) Antiprogestin mifepristone inhibits the growth of cancer cells of reproductive and non-reproductive origin regardless of progesterone receptor expression. BMC Cancer 11: 207.

18. Goyeneche AA, Seidel EE, Telleria CM (2012) Growth inhibition induced by antiprogestins RU-38486, ORG-31710, and CDB-2914 in ovarian cancer cells involves inhibition of cyclin dependent kinase 2. Invest New Drugs 30: 967-980.

19. Telleria CM, Goyeneche AA (2012) Antiprogestins in Ovarian Cancer. Ovarian Cancer - Clinical and Therapeutic Perspectives; Samir Farghaly (Eds).

20. Kaiser J (2011) Biomedicine. NIH's secondhand shop for tried-and-tested drugs. Science 332: 1492.

21. Song CW, Lee H, Dings RP, Williams B, Powers J, et al. (2012) Metformin kills and radiosensitizes cancer cells and preferentially kills cancer stem cells. Sc Rep 2: 362.

22. Breitkreutz I, Anderson KC (2008) Thalidomide in multiple myeloma--clinical trials and aspects of drug metabolism and toxicity. Expert Opin Drug Metab Toxicol 4: 973-985

23. Hicks LK, Haynes AE, Reece DE, Walker IR, Herst JA, et al. (2008) A metaanalysis and systematic review of thalidomide for patients with previously untreated multiple myeloma. Cancer Treat Rev 34: 442-452.

24. Palumbo A, Facon T, Sonneveld P, Blade J, Offidani M, et al. (2008) Thalidomide for treatment of multiple myeloma: 10 years later. Blood 111: 3968-3977.

25. Bartlett JB, Dredge K, Dalgleish AG (2004) The evolution of thalidomide and its IMiD derivatives as anticancer agents. Nat Rev Cancer 4: 314-322.

26. Fletcher I (1980) Review of the treatment of thalidomide children with limb defeciency in Great Britain. Clin Orthop Relat Res (148): 18-25.

27. Knobloch J, Ruther U (2008) Shedding light on an old mystery: thalidomide suppresses survival pathways to induce limb defects. Cell Cycle 7: 1121-1127.

28. Nadal E, Olavarria E (2004) Imatinib mesylate (Gleevec/Glivec) a moleculartargeted therapy for chronic myeloid leukaemia and other malignancies. Int $J$ Clin Pract 58: 511-516. 
29. Nimmanapalli R, Bhalla K (2002) Mechanisms of resistance to imatinib mesylate in Bcr-Abl-positive leukemias. Curr Opin Oncol 14: 616-620.

30. Melo JV, Chuah C (2007) Resistance to imatinib mesylate in chronic myeloid leukaemia. Cancer Lett 249: 121-132.

31. Grunberg SM, Weiss MH, Russell CA, Spitz IM, Ahmadi J, et al. (2006) Longterm administration of mifepristone (RU486): clinical tolerance during extended treatment of meningioma. Cancer Invest 24: 727-733.

32. Collins FS (2011) Reengineering translational science: the time is right. Sci Transl Med 3: $90 \mathrm{~cm} 17$.

33. Discovering new therapeutic uses for existing molecules. National Center for Advancing Translational Sciences.

34. Tworoger SS, Fairfield KM, Colditz GA, Rosner BA, Hankinson SE (2007) Association of oral contraceptive use, other contraceptive methods, and infertility with ovarian cancer risk. Am J Epidemiol 166: 894-901.
35. Vessey M, Painter R (2006) Oral contraceptive use and cancer. Findings in a large cohort study, 1968-2004. Br J Cancer 95: 385-389.

36. Rosenberg B, VanCamp L (1970) The successful regression of large solid sarcoma 180 tumors by platinum compounds. Cancer Res 30: 1799-1802.

37. Rosenberg B, VanCamp L, Trosko JE, Mansour VH (1969) Platinum compounds: a new class of potent antitumour agents. Nature 222: 385-386.

38. Rosenberg B, Van Camp L, Grimley EB, Thomson AJ (1967) The inhibition of growth or cell division in Escherichia coli by different ionic species of platinum (IV) complexes. J Biol Chem 242: 1347-1352.

39. Rosenberg B, Vancamp L, Krigas T (1965) Inhibition of Cell Division in Escherichia Coli by Electrolysis Products from a Platinum Electrode. Nature 205: 698-699. 